\title{
Equilibrium Tax Rates and Income Redistribution: A Laboratory Study*
}

\author{
Marina Agranov ${ }^{\dagger}$ and Thomas R. Palfrey ${ }^{\ddagger}$
}

August 7, 2015

\begin{abstract}
This paper reports results from a laboratory experiment that investigates the MeltzerRichard model of equilibrium tax rates, inequality, and income redistribution. The experiment varies the amount of wage inequality and the political process used to determine tax rates. We find that higher inequality leads to higher tax rates; the effect is significant and large in magnitude. The tax rates and labor supply functions are both quantitatively close to the theory. The result is robust to the political institution. The theoretical model of Meltzer-Richard is extended to incorporate social preferences in the form of altruism and inequity aversion, which are found to have negligible effects in the data.
\end{abstract}

\section{Introduction}

In the US and other democratic countries, taxes are decided by a democratic political process, and income tax policy in particular has enormous redistributive consequences. Much of the expenditures that are financed by income taxes are either almost entirely redistributive, such as Food Stamps or Aid to Families with Dependent Children, or have significant redistributive components, such as subsidies to education (college loans, head start, work study), public transit, and health insurance. These expenditures are generally aimed at benefiting lower income members of society, while the costs of these programs are borne in proportion to income (or, under progressive taxation, more than proportionally to income). However, standard economic analysis implies that, unless the elasticity of labor supply with respect to after-tax wages is zero for all individuals, this redistribution comes at a cost. Thus, on

${ }^{*}$ The financial support of the National Science Foundation (SES-0962802), the Russell Sage Foundation, and the Gordon and Betty Moore Foundation is gratefully acknowledged. The paper benefited from discussion and commentary at several conference and seminar presentations. We are especially grateful for comments and suggestions from Ernesto Dal Bo, John Londregan, Thomas Romer, as well as the referees and editor. Kirill Pogorelskiy provided excellent research assistance.

${ }^{\dagger}$ Division of the Humanities and Social Sciences, California Institute of Technology, Mail Code 228-77, Pasadena, CA 91125. Email: magranov@hss.caltech.edu.

${ }^{\ddagger}$ Division of the Humanities and Social Sciences, California Institute of Technology, Mail Code 228-77, Pasadena, CA 91125. Email: trp@hss.caltech.edu. 
the one hand, income taxes reduce inequality, which is generally regarded to be a positive improvement to society, but on the other hand, taxes may negatively affect efficiency of the economy through distortions in the labor market. This fundamental equity-efficiency tradeoff drives much of the political debate and polarization over economic policy, which is considered by most political scientists to be the primary dimension of political competition in modern democracies. ${ }^{1}$

There is now a rather well developed and rigorous, equilibrium-based theory addressing the positive question of how the level of income taxes are determined in the democratic society, starting with the work of Romer (1975), Roberts (1977) and Meltzer and Richard (1981). These models are based on the median voter theory developed by Black (1958) and Downs (1957). ${ }^{2}$ The equity-efficiency tradeoff in these models is captured by a distortion to labor supply created by a gap between the after-tax wage and a worker's marginal productivity. The heterogeneity in the agents' productivities is the driving force behind inequality in the pre-tax incomes in these models, as it is in the model we study in the present paper. While the theoretical implications of these models have potentially enormous economic consequences, both in terms of inequality level in society and economic efficiency, as an empirical matter, these theories are extremely difficult to test using macro field and historical data sets.

Not only is such data relatively limited, but there are open methodological issues about the extent to which these studies enable one to draw causal conclusions, as well as the deeper problem of endogeneity of the economic and political variables using historical or contemporary data. For example, one basic implication of these median voter models of tax policy is that, all else equal, greater pre-tax inequality will lead to higher taxes. At the same time the model predicts that, all else equal, higher taxes will lead to a decline in aggregate output. Besides causality issues, it is hard to pin down exactly which policies are redistributive, or more precisely, how much redistribution is associated with various policies. Moreover, the key variables, inequality, taxes, and income are all endogenous and causally intertwined. For cross-national studies, political institutions vary across countries, and in none of the systems are tax rates determined by "pure" majority rule vote. Rather there are a variety of ways of deciding taxes, ranging from decisions made by elected representatives to highly decentralized systems that more closely resemble referenda.

There have been a number of careful studies that acknowledge these difficulties and attempt to overcome them. Unfortunately, taken collectively, these studies have led to ambiguous, and sometimes conflicting conclusions. Several studies attempt to test the median voter tax hypothesis, which states that the tax rate and/or government expenditures in democracies will correspond to the ideal level of public expenditure of the median voter. Meltzer and Richard (1983) test this with data on their categorization of redistributive expenditures in the U.S. between 1936 and 1977, excluding expenditures on public goods such as public safety, defense, and infrastructure. They don't find direct evidence for the hypothesis, but find that purely redistributive expenditures are positively correlated with the ratio of

\footnotetext{
${ }^{1}$ See, for example, McCarty, Poole and Rosenthal (2006).

${ }^{2}$ The present paper focuses primarily on behavioral and positive questions about the political-economic equilibrium that determines tax policy, rather than normative concerns about optimal tax rates. Thus we explore a different set of questions than is addressed in the literature on incentive efficient tax schemes, pioneered by Mirlees (1971).
} 
mean to median income. Milanovic (2000), in a cross-sectional study of 24 democracies, also finds that income redistribution to the poor correlates with measures of income inequality, but finds little support for the median voter hypothesis. On the other hand, Perotti (1996), in his cross-sectional study of 67 countries, does not find significant evidence for a positive relationship between inequality and middle class tax rates. Thus, the overall picture is one of mixed empirical findings. While some of the findings are suggestive of a link that would be consistent with the median voter hypothesis, the link is tenuous and does not help identify the mechanism by which the median voters preferences are implemented in the political process.

Experiments offer a valuable tool for advancing our understanding of the political economy of redistribution and taxation by providing a clean test of the theoretical models in very simple environments, while preserving key incentives and tradeoffs that people face outside of the laboratory. Data created from a carefully controlled setting can be used toward the development of better models. Our experiment can be seen as one of the first attempts to study the interaction between labor market and political behavior in the laboratory, while keeping all the remaining details (political institution and distribution of productivities) constant and varying one parameter at a time. While the environment in the laboratory eliminates many of the confounding factors that are present in the more complex phenomena of fiscal policy making and labor supply in large economies, experiments have a significant advantage over empirical research using historical time-series or cross-sectional data in the evaluation of the theoretical models that economists develop in order to better understand these complex phenomenon. At the same time, although the experiment we conduct provides a sharp test of the basic theory, the existence of those many confounding factors makes us reluctant to make any grand claims about voting over redistributive taxes in mass electorates and legislative bodies or aggregate labor supply responses to income tax rates in large economies.

The experiment we report in this paper explores questions about the equity-efficiency tradeoff vis-a-vis redistributive taxation, the equilibrium effect of wage inequality on income tax rates, and the median voter hypothesis about the political economy consequences of voting over taxes. Our laboratory environment is designed to correspond to the Meltzer-Richard model. The individuals participating in our experiment operate in two interconnected environments: a political environment, where the level of taxation is determined, and a labor market (economic environment), in which, given an income tax schedule, individuals with varying wage rates choose labor supply that generates pre-tax income. Because of the redistributive effect of income taxation and because individuals differ in their productivities and hence their incomes, individuals in our experiment have different indirect preferences for the level of taxation and these preferences depend upon the distribution of productivities in the economy. Political institutions are the means by which these heterogeneous preferences are aggregated into a public decision on the tax rate. However, because the tax rate in turn affects the amount of income that is generated by the private economy, agents' preferences for redistribution themselves are endogenous and depend on aggregate labor supply responses to taxes.

The experiment is motivated by three distinct considerations. The primary motivation was summarized above: the large empirical literature devoted to studying these questions about the equity-efficiency tradeoff and in particular the median voter hypothesis that implies greater inequality leads to higher taxes, has not succeeded in coming to any consensus 
about any of the important questions raised by the theoretical political models of redistributive taxation. Our experiment can address these theoretical issues by providing data from a simple environment where preferences, technology, and the political process are tightly controlled, leading to sharp theoretical predictions. By exogenously controlling the level of inequality, we can address the causal question of how the degree of inequality in the economy affects the level of redistributive taxation.

A second consideration concerns the role of the specific set of institutions that implements democratic outcomes. One of the shortcomings of the classic political economy models of income taxation is that they are completely silent about the mechanics of the political process by which a tax rate is chosen. The models simply assume that the tax rate preferred by the median voter will emerge, as if by an invisible political hand. To address this, our experimental design compares the tax rates that emerge under two canonical majoritarian political processes that correspond to much different extensive form games: direct democracy and representative democracy. In the direct democracy mechanism, the median voter's preferred policy is elicited directly ${ }^{3}$, while in the representative democracy system voters choose in an election between two office-motivated candidates who compete by choosing tax rates as their platforms.

A third consideration concerns the potentially important effects of direct preferences for redistribution. The standard political economy approach described above characterizes indirect preferences for redistribution, based on the assumption that voters are completely selfish. There is a substantial empirical literature on direct preferences for redistribution, largely addressing questions of cross-cultural differences in preferences for equality, tolerance of inequality, or interdependent preferences (see Alesina and Giuliano (2011)). ${ }^{4}$ Redistributive taxation is an environment where social preferences can naturally influence behavior and outcomes. With this in mind, we extend the basic model to characterize the equilibrium effects of social preferences, and test for such effects in the data.

We have three main results, which map directly back to the three motivations described above. The first result is that the implemented tax rates in the experiment closely track the preferences of the median productivity worker, providing support for the median voter theory of equilibrium tax rates. Higher tax rates lead to lower aggregate labor supply and lower total income, and the observed voting decisions indicate that the preferences of voters over tax rates take into account this equity-efficiency tradeoff. As a consequence, we find that higher inequality leads to significantly more income redistribution through higher taxation.

The second main finding is that the first result is robust to the specific political institution used to set the tax rates: we observe very similar behavior and outcomes under direct democracy and representative democracy. Observation of choice behavior of voters in each political mechanism (direct and representative democracy) allows us to back out estimates of the revealed-preferred ideal points of different voter types, and in both institutions, the estimated ideal tax rates are monotone in productivity as predicted by the theory, with less

\footnotetext{
${ }^{3}$ This mechanism has been used in tax referendums in the U.S. See Holcombe (1977) and Holcombe and Kenny $(2007,2008)$.

${ }^{4}$ There is also abundant evidence from laboratory experiments suggesting a role of direct preferences over redistribution, or social preferences, in economic decision making in environments where inequality plays a role. See, for example, Andreoni and Miller (2002), Bolton and Ockenfels (2000), Fehr and Schmidt (1999), Fisman et al. (2007), Palfrey and Rosenthal (1988).
} 
productive (low wage) individuals preferring higher taxes.

The third main finding is that direct preferences for redistribution, in the form of either altruism or inequity aversion, affect neither individual labor supply decisions nor the implemented tax rates in our data. The quantitative measures of observed labor supply and the average tax rates in the experiment are not significantly different from the standard equilibrium model with selfish preferences. We construct a model with homogeneous preferences to estimate the altruism and inequity aversion parameters, using the data on labor supply and voting decisions. The estimation fails to reject the hypothesis that the social preference parameters are equal to zero, implying that social preferences apparently do not play an important role in either labor supply responses to taxes, or preferences over redistribution, at least in our laboratory environment.

In the remainder of this section, we discuss some related experimental literature. Section 2 presents the equilibrium model of redistributive taxation (with selfish preferences), which serves as the theoretical foundation for the main hypotheses about about labor supply functions and implemented tax rates for the experiment. Section 3 presents the experimental design and procedures. The results are presented in Sections 4 and 5.

\section{$1.1 \quad$ Related Literature}

There is an extensive experimental literature in economics aimed at measuring preferences for redistribution. Some studies abstract away from efficiency considerations and focus on selfinterest versus fairness (e.g. Forsythe et al. (1994)), while more recent papers incorporate efficiency by varying exogenously the size of the total pie (Andreoni and Miller (2002), Fisman et al. (2007)). Bolton and Ockenfels (2006) report series of voting games, in which subjects are confronted with two distributions of incomes: one that promotes efficiency and a second that promotes equity. Tyran and Sausgruber (2006) offer evidence that inequality averse social preferences may explain voting behavior over non-distortionary redistribution, in an experiment where subjects were endowed with one of two different income levels and vote on a fixed amount of redistribution. Hochtl et al. (2012) show that the ability of inequity aversion to explain voting behavior on redistribution may depend on the pre-tax distribution of income. In all the papers described above, the amount of resources to be distributed is fixed exogenously and participants can only decide how to reallocate this surplus. In our experiments subjects' labor market decisions determine the total surplus generated, so both the total size of the pie and the distribution of income is endogenous.

Four recent studies are more closely related to our paper. Konrad and Morath (2011) is the only other experiment that is motivated by the Meltzer-Richard model. Both the focus and the methodology is different. They study how how prospects of income mobility may affect preferences for redistributive taxes in an individual decision-making experiment without strategic interaction between subjects. In particular, each human subject is paired with two computers who choose actions that maximize their own earnings; human subjects are aware of the computers' strategies. In the one treatment without mobility observed tax rates are in line with theoretically predicted ones. The important methodological difference in their study is the use of computerized agents in place of strategic interaction between human subjects. Esarey et al. (2012) study preferences for redistribution in a real effort experiment but address a much different question. They focus on the linkage between these preferences 
and ideological positions elicited from a survey. Preferences over tax rates are elicited by using the median voting rule to select group tax rate. The authors find that preferences for redistribution were largely driven by self-interest. Durante et al. (2014) investigate how preferences for redistribution vary with social preferences, risk aversion, self-interest and the source of pre-tax inequality. The main finding is that subjects' preference for redistribution decreases substantially when the initial distribution of endowments is determined based on the task performance (earned income) rather than randomly (luck). Grosser and Reuben (2013) report two experiments where subjects earn income in a double action market. In the first experiment trading profits are redistributed according to one of several exogenously fixed rules. The goal is to see whether equal-share redistribution affects trading efficiency. In a competitive equilibrium there should be no such effect in theory, and they observed only small effects. In the second experiment, redistribution is endogenous and determined by candidate competition as in our study. Because the taxes are non-distortionary and the median voter has low income, the theoretical equilibrium tax rate is $100 \%$, which is close to what is observed.

\section{Model and Theoretical Predictions}

In this section we lay out the primitives of the model and derive equilibrium under the assumption that agents are purely selfish. ${ }^{5}$ The economy consists of $n>1$ agents. Agents operate in a perfectly competitive and frictionless labor market and also participate in a democratic political process that determines taxes which in turn affect labor decisions.

We start by discussing the decision problem of an agent in the labor market assuming that the tax rate is fixed. Then we characterize the majority rule equilibrium tax rate, by deriving the induced preferences of voters, assuming rational expectations about how aggregate labor supply responds to changes in the income tax rate.

The Labor Market. Agent $i$ is endowed with productivity $w_{i}$. Individuals are identical in all other respects. The difference in choice of labor and consumption arise solely because of the differences in productivity. An agent with productivity $w_{i}$ who supplies $x_{i}$ units of labor earns pre-tax income $y_{i}=w_{i} x_{i}$ and bears an effort cost of $\frac{1}{2} x_{i}^{2}$ which represents the tradeoff between labor and leisure. Income and costs are measured in units of consumption. In addition, each agent pays a fraction $t$ of earned income in taxes. Tax revenues are redistributed in equal shares. ${ }^{6}$ Thus the payoff $U_{i}$ of agent $i$ consists of three parts: after-tax disposable income, cost of labor, and an equal share of collected taxes, where the latter depends on the entire profile of productivities, $w=\left(w_{1}, \ldots, w_{n}\right)$ and labor supply decisions $x=\left(x_{1}, \ldots, x_{n}\right)$ :

$$
U_{i}\left(w_{i}, x_{i}, t\right)=(1-t) \cdot w_{i} x_{i}-\frac{1}{2} x_{i}^{2}+\frac{1}{n} \sum_{j=1}^{n} t \cdot w_{j} x_{j}
$$

\footnotetext{
${ }^{5}$ Theoretical predictions for two alternative models of social preferences are derived in Section 5.2.

${ }^{6}$ Equivalently, taxes are used to finance a level of public good according to the linear technology, $y=$ $\frac{1}{n} \sum_{j=1}^{n} t \cdot w_{j} x_{j}$, and all agents value the public good according to the function $V(y)=y$, which corresponds to the last term of equation (1).
} 
Given the tax rate $t$, agent $i$ chooses labor supply $x_{i}$ that maximizes (1) above, taking $x_{-i}$ as given. The utility function is concave, and the unique optimal labor supply for individual $i$ is characterized by the first order condition:

$$
x_{i}^{*}\left(w_{i}, t\right)=\left(1-\frac{n-1}{n} t\right) w_{i}
$$

Thus, all productive agents (i.e., $w_{i}>0$ ) have positive labor supply for all tax rates, $t \in$ $[0,1]$. Labor supply is declining in the tax rate and is proportional to a worker's productivity. Hence, pre-tax income is proportional to the square of productivity.

Equilibrium Tax Rates Under Majority Rule. We next derive the indirect preferences of agents over tax rates, and characterize the majority rule equilibrium.

The equilibrium payoff of agent $i$ when the tax rate $t$ is implemented and all other agents follow the behavior prescribed by the equilibrium in the labor market is:

$$
U_{i}^{*}\left(w_{i}, t\right)=\frac{1}{2}\left((1-t)^{2}-\frac{t^{2}}{n^{2}}\right) w_{i}^{2}+\frac{t}{n}\left(1-\frac{n-1}{n} t\right) Z
$$

where $Z=\sum_{j=1}^{n} w_{j}^{2}$ denotes the aggregate income of the economy if the tax rate is $t=0$.

Our first result, Proposition 1, characterizes preferences of agents over tax rates and derives the majority rule equilibrium tax rate.

Proposition 1: Agents' preferences over tax rates satisfy the following properties: ${ }^{7}$

1. Single-peakedness: for any $w_{i}$, there exists $t_{i}^{*} \in[0,1]$ such that $U_{i}^{*}\left(w_{i}, t\right)<U_{i}^{*}\left(w_{i}, t^{\prime}\right)$ for all $t<t^{\prime} \leq t_{i}^{*}$ and $U_{i}^{*}\left(w_{i}, t\right)<U_{i}^{*}\left(w_{i}, t^{\prime}\right)$ for all $t_{i}^{*} \geq t^{\prime}>t$

2. Ideal points are ordered by productivity: $t_{i}^{*} \leq t_{j}^{*} \Leftrightarrow w_{i}>w_{j}$

3. The majority rule equilibrium tax rate, $t_{m}^{*}$, is given by the ideal tax rate of the median productivity worker:

$$
t_{m}^{*}=\left[\begin{array}{lll}
\frac{n^{2}}{n^{2}-1} \cdot \frac{\frac{1}{n} Z-w_{m}^{2}}{\frac{2}{n+1} Z-w_{m}^{2}} & \text { if } \quad w_{m}^{2} \leq \frac{1}{n} Z \\
0 & \text { if } \quad w_{m}^{2}>\frac{1}{n} Z
\end{array}\right.
$$

The intuition for this characterization is straightforward. Agents with lower productivity prefer higher taxes, because they enjoy substantial redistributive benefits which for the most part come from the tax payments of the higher productivity, and hence higher income, agents. In contrast, agents with higher productivity prefer lower taxes (or no taxes at all), because they end up subsidizing the large portion of the tax revenues from which they receive back

\footnotetext{
${ }^{7}$ The proof is in Appendix A. These properties are central in the theoretical literature that studies the political economy of redistributive taxation. Romer (1975) assumes that agents have Cobb-Douglas preferences over consumption and leisure and derives conditions under which the preferences of agents are single-peaked in the tax rate. Roberts (1977) derives a more general condition that guarantees that ideal points are inversely ordered by income. Meltzer and Richard (1981) assume the regularity condition of Roberts (1977).
} 
only a small part in benefits. Specifically, voters with below average income prefer positive tax rates, while voters with above average income prefer zero tax rates.

Single-peakedness and monotonicity of ideal tax rates with respect to productivities, combined with the majority rule, imply that the agent with the median productivity (median voter) is decisive. Put differently, the tax rate specified in equation (4), which is the tax rate most preferred by the median voter, is the unique tax rate that is majority preferred to any other tax rate, and is therefore a Condorcet winner. This result echoes the median voter theorem from the spatial model of electoral competition.

Notice that total income in equilibrium is $\sum_{i=1}^{n} U_{i}^{*}\left(w_{i}, t\right)=\frac{1}{2}\left(1-\frac{(n-1)^{2}}{n^{2}} t^{2}\right) \sum_{i=1}^{n} w_{i}^{2}$ and it is maximized when $t=0$ since taxes are distortionary.

A natural next question that arises in this setup is: How do tax rates compare across economies that differ in the distribution of productivity levels of its agents? The following corollary to Proposition 1 provides an answer to this question.

Corollary. Consider two economies with $n$ individuals, which differ only in the profile of productivities: $w^{A}$ in economy $\mathrm{A}$ and $w^{B}$ in economy $\mathrm{B}$, and suppose that $w_{m}^{A}=w_{m}^{B}$. Then, $t^{* A}=t^{* B}=0$ if and only if $w_{m}^{2}>\frac{1}{n} Z^{A}>\frac{1}{n} Z^{B}, t^{* A}>t^{* B}=0$ if and only if $\frac{1}{n} Z^{A}>w_{m}^{2}>\frac{1}{n} Z^{B}$ and $t^{* A}>t^{* B}>0$ if and only if $\frac{1}{n} Z^{A}>\frac{1}{n} Z^{B}>w_{m}^{2}$.

The corollary can be interpreted in terms of inequality in productivities as measured approximately by the variance of worker productivities. To see this, notice that in the special case where the median productivity equals the mean productivity, $\frac{1}{n} Z$ is approximately equal to the variance of $w_{i}$, with the approximation being arbitrarily close for large $n$. In this case, an increase in the variance that leaves the mean unchanged will lead to a higher equilibrium tax rate. The tax rate chosen by the median voter will be higher in the economy in which the productivity levels are more unequal as captured by this variance-related measure, $\frac{1}{n} Z$. Also, if the distribution of productivities in economy $\mathrm{A}$ is more skewed than the one in economy $\mathrm{B}$ then $\frac{1}{n} Z^{A}>\frac{1}{n} Z^{B}$ and we would expect (weakly) higher taxes in economy $\mathrm{A}$ than in economy $B$. The intuition for this result comes from the fact that tax revenues are rebated back to all agents in equal shares. When higher productivity agents become more productive, they supply more labor and, thus, contribute more to the total tax revenues. Therefore, the median voter would prefer higher taxes and more redistribution since an increase in the tax rebate associated with an increase in tax rates outweighs the decrease in after-tax disposable income.

\section{Experimental Design}

Our design has two different treatment dimensions. The first dimension varies the level of wage (productivity) inequality among the agents in the economy in order to test one of the main predictions of the theoretical model, that greater inequality leads to more redistributive taxation. We have two distributional treatments, which we call Low inequality and High inequality. The productivity of the median voter is the same in both treatments $\left(w_{m}^{\text {Low }}=\right.$ $\left.w_{m}^{\text {High }}\right)$, but the relevant inequality measure is higher in High than Low $\left(Z^{\text {Low }}<Z^{\text {High }}\right)$. Both have interior equilibrium tax rates, with $0<t^{* \text { Low }}<t^{* \text { High }}<1$.

Table 1 specifies the values used in each treatment and lists the ideal tax rates for all 
agents, assuming selfish preferences. In both of the distributional treatments, there are five individuals, each with a different wage rate. The only difference between parameters in the High and Low inequality treatments is the productivity of the most productive agent.

Table 1: Parameters and Equilibrium Tax Rates

\begin{tabular}{ccc|ccc}
\hline \hline \multicolumn{2}{c|}{ High Inequality Treatment } & \multicolumn{3}{c}{ Low Inequality Treatment } \\
Agent & Productivity & Ideal Tax Rate & Agent & Productivity & Ideal Tax Rate \\
\hline 1 & 2 & 0.62 & 1 & 2 & 0.62 \\
2 & 6 & 0.59 & 2 & 6 & 0.54 \\
3 & 10 & $\mathbf{0 . 5 3}$ & 3 & 10 & $\mathbf{0 . 2 8}$ \\
4 & 14 & 0.37 & 4 & 14 & 0.00 \\
5 & 35 & 0.00 & 5 & 18 & 0.00 \\
\hline \hline
\end{tabular}

The second dimension of the design varies the political mechanism for implementing a tax rate. We consider two very different competitive democratic institutions for determining the tax rate. As explained in the introduction, the motivation for looking at two different institutions is that the theory does not specify an extensive form for the majoritarian process. Because the are many possible "democratic" mechanisms in practice, it is important to see if the results depend on the institutional details, or if the results are robust across different mechanisms. In a world with perfect information and perfect optimization by all agents, the subgame perfect equilibrium in both regimes theoretically could produce the same tax rate outcome, which will correspond to the median voter ideal point. The two institutions we use in the experiment are direct democracy and representative democracy. The two institutions were designed such that the median voter's ideal tax rate is the outcome of the unique subgame perfect equilibrium in both regimes. Details are given in Section 3.1 below.

\subsection{Experimental Procedures}

All the experiments were conducted at the CASSEL (California Social Science Experimental Laboratory) using students from the University of California, Los Angeles. Subjects were recruited from a database of volunteer subjects. ${ }^{8}$ Nine sessions were run, using a total of 228 subjects. No subject participated in more than one session. We used a between subjects design, so each subject participated in only one treatment. Table 2 summarizes the sessions.

The experimental currency was called tokens. Each token a subject earned was converted to dollars at an exchange rate of $\$ 1=200$ tokens. $^{9}$ Total earnings for a subject was the sum of earnings across all periods in the session, plus a $\$ 10$ show up fee. Average earnings, including the show up fee, were approximately $\$ 32$ with a standard deviation of $\$ 7.8$. Sessions lasted approximately two hours on average.

\footnotetext{
${ }^{8}$ The software for the experiment was developed from the open source Multistage package, available for download at http://software.ssel.caltech.edu/.

${ }^{9}$ The exchange rate was higher $(\$ 1=100$ tokens $)$ for the Low inequality treatment because the potential theoretical earnings were lower.
} 
Table 2: Experimental Design

\begin{tabular}{lcc}
\hline \hline Regime & High Inequality & Low Inequality \\
\hline DD & 2 sessions (60 subjects; 12 groups) & 3 sessions (70 subjects; 14 groups) \\
RD & 2 sessions (49 subjects; 7 groups) & 2 sessions (49 subjects; 7 groups) \\
\hline \hline
\end{tabular}

Upon arrival to the laboratory, subjects were divided into groups of five or seven agents: five in the DD sessions and seven in the RD sessions. Five subjects in each group performed the role of agents and two additional subjects in the RD sessions performed the role of the candidates. Each agent in a group was assigned one of the five productivities (see Table 1). Productivity assignments and the group assignments were fixed for the whole duration of the session. At the very beginning of the session each agent was told their own productivity, but also told the productivity of each of the other four agents.

There were two parts in each session. In the first part, which lasted for 10 periods, subjects gained experience with the labor market. In the second part of the experiment, which also lasted for 10 periods, depending on the session subjects participated in either the $\mathrm{DD}$ or the $\mathrm{RD}$ game. Instructions for the second part of the session were given to the participants only after they finished the first part. ${ }^{10}$ We will now describe the specific experimental procedures that were common to all the sessions and then describe how different political regimes were implemented.

In the first part of a session, at the beginning of each period agents were informed of the tax rate for that period. Then they chose how much labor to supply without knowing what other subjects in their group chose. ${ }^{11}$ Labor supply decisions were allowed to be any number between 0 and 25 with up to two decimal places. ${ }^{12}$ After all five agents had made their choice, subjects received feedback that specified the labor supply of each agent in their group, and an agent's own payoff was displayed on the screen, broken down into three parts: after-tax income, the quadratic cost of labor, and their tax rebate (equal share of collected taxes). After the period was over, the group moved on to the next period which was identical to the previous one except for the tax rate imposed at the beginning of the period. In this training part of the session, subjects went through different possible tax rates, in the following order: $0.50,0.15,0.70,0.62,0.35,0.05,0.27,0.75,0.90,0.20$.

To help subjects calculate hypothetical earnings from different labor supply choices, they were provided with a built-in calculator that appeared on their monitors. To use the calculator, subjects had to enter two numbers: a labor supply decision and a guess for the total taxes collected from the other members in their group. Then, the calculator computed

\footnotetext{
${ }^{10}$ Appendix B contains the instructions for the DD High inequality treatment.

${ }^{11}$ The terminology in the experiment avoided reference to work, effort, productivity or other terms associated with labor markets. The individual labor supply decision was called the "investment level" and productivities/wages were called "values". Pre-tax labor income was called "investment earnings".

${ }^{12}$ Recall that the optimal choice of labor given the tax rate is $x_{i}\left(w_{i}, t\right)=\left(1-\frac{n-1}{n} t\right) \cdot w_{i}=(1-0.8 t) \cdot w_{i}$. Thus, for all agents and for all tax rates, the theoretically optimal choice of labor is away from the boundaries (strictly below 25 and strictly above 0), except for the agent with highest productivity in High inequality treatment $\left(w_{i}=35\right)$. Agent with $w_{i}=35$ should choose $x_{i}(35, t)=25$ for any tax rate below 0.375 . In equilibrium, the upper bound of 25 is not binding for either parameter set.
} 
the payoff of the subject in this hypothetical scenario taking into account the current tax rate in this training period and the wage assigned to the subject.

Experimental protocol specific for Direct Democracy. In the second part of the DD sessions, at the beginning of each period each agent was asked to submit a proposal for the tax rate. The median proposal (third lowest tax rate) was announced to all subjects and implemented in that period. ${ }^{13}$ After the tax rate was determined, subjects chose their labor supply as in the first training part. Again, after the tax rate was determined, subjects could use the on-screen calculator to evaluate different hypothetical scenarios before they submitted their labor supply decision. This two-stage process was repeated 10 times (10 periods).

\section{Experimental protocol specific for Representative Democracy.}

Representative democracy (RD) is implemented as Downsian candidate competition, by introducing two additional players into the game, both of whom are purely office-motivated candidates, with no private preferences over tax rates. This leads to a three stage game. In the first stage, the two candidates simultaneously submitted tax rate proposals. In the second stage, voters observed the two candidates' tax rate proposals and voted for one of the candidates, with no abstention. The tax rate proposal submitted by the candidate who received a majority of votes was implemented for that period. In the third stage, the process was the same as in the DD sessions: agents observed the tax rate, chose how much to work and then got feedback for that period. The only source of earnings for the candidates in the last 10 periods was winning elections: the winning candidate in a period earned 200 tokens and the loser earned 0 tokens. This payoff structure aimed to incentivize candidates to propose the ideal tax rate of the median voter, since, in theory, it defeats any other proposed tax rate if all agents are choosing their labor supply decisions optimally. As in the DD regime, once the tax rate for the period was determined, agents could use the built-in calculator to evaluate hypothetical scenarios before submitting the final labor decision. ${ }^{14}$

The first (training) 10 periods of the RD sessions were the same as in the DD sessions except that the two candidates were also given a task. In order to focus the candidates' attention during these periods, in each period each candidate was randomly assigned one of the agents, was told the agent's productivity and the tax rate for that period, and then was asked to guess the labor supply of that agent. A candidate earned 100 tokens for guessing correctly and 0 tokens for guessing incorrectly, where the correct guess was defined as within 2 points of the actual labor supply decision of that agent in that period. At the end of each period, the candidates observed all the labor choices of all five agents in their group.

\section{Results}

In this section we test the main predictions of the theoretical model presented in Section 2 combining the data from both political regimes. We investigate the median voter hypothesis,

\footnotetext{
${ }^{13}$ It is well known (Moulin, 1980) that under this mechanism every voter has a dominant strategy to propose his or her ideal tax rate.

${ }^{14}$ Additional RD sessions were also conducted with an alternative protocol that was problematic because it eliminated the learning phase and limited comparability with the DD sessions. Those sessions exhibited slower convergence to the theoretically predicted tax rates, but were otherwise similar.
} 
the effect of inequality on redistribution, aggregate labor market behavior, and the equityefficiency tradeoff. In Section 5 we extend the analysis of results by comparing behavior and outcomes under both DD and RD regimes and testing for the effects of social preferences.

\subsection{Implemented Taxes}

The theoretical results of Section 2 imply the hypothesis that greater inequality leads to higher taxes. Hence, we should observe higher tax rates in our High inequality treatment than in our Low inequality treatment. The data strongly support this hypothesis. Table 3 presents summary statistics of implemented taxes in each inequality treatment. ${ }^{15}$ Figure 1 shows the evolution of the average implemented tax for the same part of the game.

Table 3: Implemented Tax Rates

\begin{tabular}{lcccc}
\hline \hline & High Inequality, $t^{*}=0.53$ & \multicolumn{2}{l}{ Low Inequality, $t^{*}=0.28$} \\
& mean (st err) & median & mean (st err) & median \\
\hline Implemented Taxes & $0.50(0.03)$ & 0.55 & $0.26(0.03)$ & 0.25 \\
\hline \hline
\end{tabular}

Note. Robust standard errors are in parentheses, clustered by group.

Table 3 shows that taxes are higher in the High than in the Low Inequality treatment, and the effect is highly significant. This result is also confirmed statistically by regressing the implemented tax rates on a dummy variable for the High inequality treatment. The estimated coefficient $(0.24)$ is positive and highly significant $(p=0.00) .{ }^{16}$

The second prediction of the theory is the median voter hypothesis, that for both inequality treatments the ideal tax rate of the median productivity agent will be implemented. Our data provide support for this hypothesis. On average, in both inequality treatments taxes converge to the ones predicted by the theory almost exactly (see Figure 1). This is confirmed statistically for each inequality treatment separately, based on the means and standard errors reported in Table 3.

Result 1: In both inequality treatments the implemented tax rates are not significantly different from the ideal tax rate of the median productivity worker, as given in Proposition 1. Thus we find that tax rates are significantly higher when inequality is high.

\footnotetext{
${ }^{15}$ Throughout Section 4, we pool the data from the DD and RD treatments and focus on the last 10 periods of each session, which is the portion of the data where the tax rates are determined endogenously by either the DD or RD mechanism. The more extended data analysis in section 5 will show that pooling across the two institutional treatments is justified.

${ }^{16}$ In fact, as Figure 1 clearly shows, in every single period tax rates are higher in the High inequality treatment than in the Low Inequality treatment. Using a Wilcoxon rank-sum test performed period-byperiod, the distribution of taxes in the High Inequality treatment is significantly different from the Low Inequality treatment in 9 out of 10 periods at the $5 \%$ significance level (the exact p-values are reported in Table 11 in Online Appendix 3).
} 
Figure 1: Implemented Taxes, dynamics

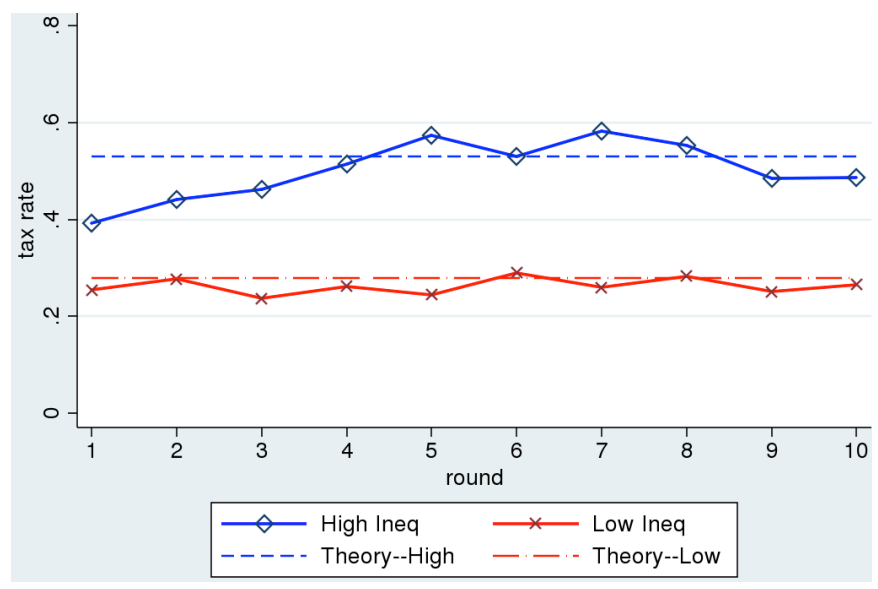

\subsection{Labor Supply}

Table 4 reports the mean difference between actual labor choices of agents and the predicted ones, broken down by productivity level and inequality treatment. The data show that behavior of agents in the labor market is close to that predicted by theory. For each tax rate and each subject, the predicted value is obtained from equation 2. For the High inequality treatment we have 19 groups and therefore have 190 observations for each productivity level; for the Low inequality treatment we have 21 groups and 210 observations for each productivity level. As reflected in the table, there is a general pattern of oversupply by low wage workers and undersupply by high wage workers. Most of these differences are small in magnitude and insignificant, with one clear exception. The highest wage workers $(w=35)$ in the High Inequality treatments on average supplied labor by nearly 3 units below the theoretical optimum. In contrast, for the highest productivity agents $(w=18)$ in the Low Inequality treatments this undersupply was of a much smaller magnitude and not significantly different from zero.

Table 4: Mean Differences Between Observed and Predicted Labor Supply

\begin{tabular}{lcc}
\hline \hline & High Inequality & Low Inequality \\
\hline Productivity 2 & $0.59(0.38)$ & $0.30(0.24)$ \\
Productivity 6 & $0.09(0.13)$ & $0.00(0.18)$ \\
Productivity 10 & $0.34(0.34)$ & $0.32(0.18)$ \\
Productivity 14 & $0.18(0.12)$ & $0.04(0.24)$ \\
Productivity 18 & & $-0.40(0.37)$ \\
Productivity 35 & $-2.67^{*}(1.11)$ & \\
\hline \hline
\end{tabular}

Note. Robust standard errors are in parentheses, clustered by subject. ${ }^{*} p<0.05$

To estimate the labor supply functions of the agents, we define the normalized labor supply function, $\mathrm{L}(\mathrm{t})$, as: $L(t) \equiv \frac{x_{i}^{*}\left(w_{i}, t\right)}{w_{i}}=1-\frac{n-1}{n} t$. Table 5 reports the Tobit estimates 
Table 5: Estimated Normalized Labor Supply Functions

\begin{tabular}{lcccc}
\hline \hline Productivity & $a$ & $p$-value & $b$ & $p$-value \\
\hline 2 & $1.04(0.22)$ & 0.86 & $-0.37(0.45)$ & 0.33 \\
6 & $0.98(0.05)$ & 0.69 & $-0.73(0.10)$ & 0.50 \\
10 & $0.99(0.03)$ & 0.73 & $-0.69(0.09)$ & 0.20 \\
14 & $0.99(0.02)$ & 0.79 & $-0.76(0.05)$ & 0.41 \\
18 & $0.96(0.05)$ & 0.45 & $-0.73(0.13)$ & 0.61 \\
$35(t>0.36)$ & $0.97(0.12)$ & 0.79 & $-0.83(0.19)$ & 0.86 \\
$35(t<0.36)$ & $0.64(0.08)$ & 0.41 & $-0.42^{*}(0.20)$ & 0.04 \\
\hline \hline
\end{tabular}

Note. Robust standard errors in the parentheses, clustered by subject. ${ }^{*} p<0.05$

obtained by regressing observed normalized labor supply $\left(\frac{x_{i}}{w_{i}}\right)$ on a constant and the tax rate. We do this separately for each productivity level, pooling across the two inequality treatments. Because we have 40 groups and 10 observations per group, this gives us 400 observations for each of the four lower productivity levels is (which are the same in both High and Low inequality treatments) and 190 observations for $w=35$ agents and 210 observations for the $w=18$ agents. For the highest productivity worker in the High inequality treatment $\left(w_{i}=35\right)$, the constraint $x_{i} \leq 25$ is binding if the tax rate is sufficiently low $(t \leq 0.375)$. So we run separate regressions for $t \leq 0.375$ and $t>0.375$ for this one class of worker-voters. Thus, the table reports the estimates of the constant term $a$ and the coefficient on the tax rate $b$ for a total of seven different regressions. According to the theoretical normalized labor supply equation derived for selfish agents, the estimates for the first six (unconstrained) regressions are predicted to be $a=1$ and $b=-\frac{n-1}{n}=-0.8$. For the constrained regression reported in the last row, the predicted estimates were $a=0.71$ and $b=0$.

The results reported in Table 5 are largely consistent with the findings from Table 4 and very close to the prediction labor supply in equation 2. The estimated constant terms and coefficients are not significantly different from the predicted ones at the $5 \%$ level with one exception. The one exception is the estimated slope of the response to the tax rate for the highest productivity agent $(w=35)$ when constraint $x_{i} \leq 25$ is binding. The estimated slope is significantly negative, which reflects the undersupply of labor by the highest productivity workers, as also reported in the last row of Table 4.

\section{Result 2: Labor supply decisions by agents are approximately optimal and consistent with the theoretical labor supply functions given in equation 2 .}

\subsection{Welfare}

There are two dimensions to consider in the welfare analysis of redistributive taxation: equity (or related notions of distributive justice) and efficiency. There is a tradeoff between these two dimensions, and both are jointly determined by the tax rate in the political sector and the labor supply decisions made in the economic sector. Thus, the welfare analysis must consider the combined political economy effects in the two sectors. The tradeoff is explicitly modeled in the theoretical framework we use: the more pre-tax income is going to be redistributed, 
the less labor will be supplied. Assuming that each worker chooses his labor supply optimally given the tax rate, we can construct an equity-efficiency frontier, for any particular measure of equity and efficiency. We use one minus the post-tax Gini coefficient as our measure of equity, and total income as the measure of efficiency. ${ }^{17}$ Using these measures, we define the equity-efficiency frontier as the locus of points in this two dimensional space corresponding to after tax equity-efficiency pairs that would arise from optimal labor supply behavior as we vary tax rates from 0 to 1 . We use this as a benchmark with which to compare the actual equity-efficiency tradeoff that is observed in the experiment.

Figure 2: Equity-Efficiency Frontier
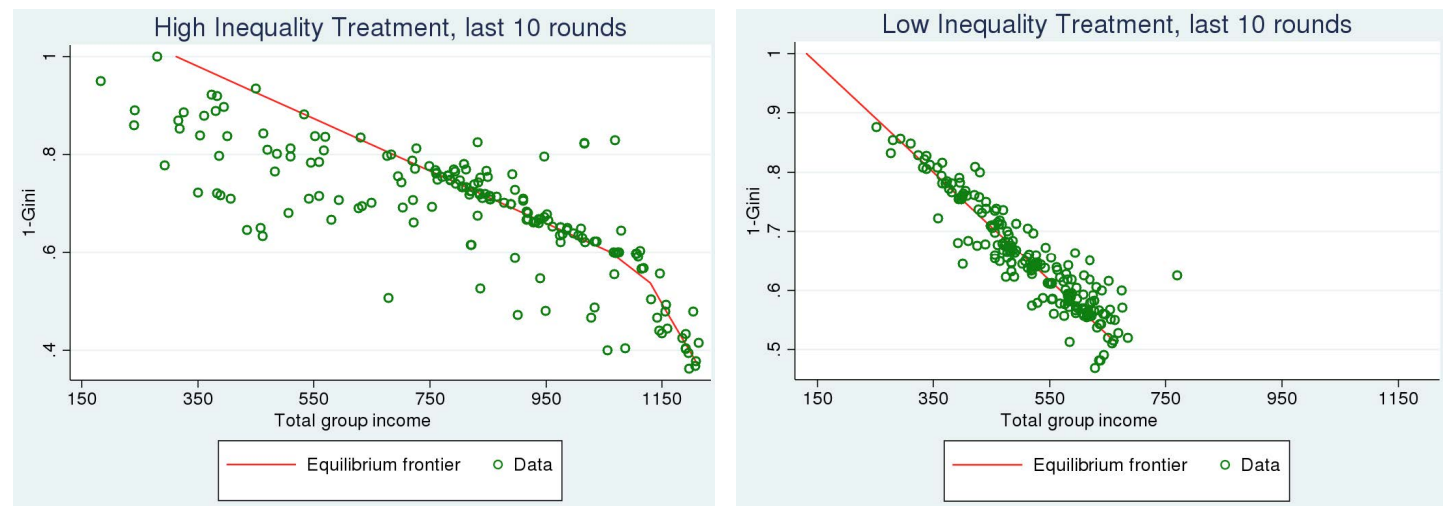

Figure 2 displays all the equity-efficiency pairs for all group outcomes in the low inequality and high inequality treatments, respectively. The solid line in the figures marks the frontier with the upper left of the frontier corresponding to $t=1$ and the lower right of the frontier corresponding to $t=0 .{ }^{18}$ Table 6 below compares the theoretical equilibrium gini coefficient (equity) and total income (efficiency) with the averages across all the equity-efficiency pairs, separately for the two inequality treatments, with group-clustered standard errors in parentheses. There is no significant difference between the theoretical equity-efficiency pairs and the observed means except for efficiency in the high inequality treatment $(p<0.05)$, which is below the theoretical level and consistent with the labor supply findings reported in Table 5 .

From a slightly different perspective, Figure 3 displays total tax revenues as a function of the tax rate $t$. The solid line represents the theoretical Laffer curve, derived under the assumption that all agents supply labor optimally given the tax rate, while the data observed in the experiments are marked as the circles. This graph is essentially a different projection of the three-dimensional picture that summarizes the relation between tax rates, efficiency and equality in the economy.

These findings can be summarized as follows. First, Figure 2 shows that, consistent with the theoretical equity-efficiency tradeoff, higher tax rates lead to lower aggregate labor

\footnotetext{
${ }^{17}$ There are alternative measures as well, such as the variance of the income distribution to measure inequality or netting out the effort costs of labor in the measure of efficiency. These alternative measures lead to similar conclusions.

${ }^{18}$ The frontier as we have defined it does not represent the boundary of feasible equity-efficiency pairs. In principle, workers are free to supply 25 units of labor for any tax rate, but doing so is not consistent with equilibrium in our labor market.
} 
Table 6: Equity-Efficiency Tradeoff

\begin{tabular}{|c|c|c|}
\hline \multicolumn{3}{|c|}{ High Inequality treatment } \\
\hline & Equilibrium & Mean Observed (std err) \\
\hline Tax Rate & 0.53 & $0.50(0.03)$ \\
\hline Gini coefficient & 0.31 & $0.32(0.019)$ \\
\hline Total group income & 899.14 & $818.32(40.99)$ \\
\hline \multicolumn{3}{|c|}{ Low Inequality treatment } \\
\hline & Equilibrium & Mean Observed (std err) \\
\hline Tax Rate & 0.28 & $0.26(0.03)$ \\
\hline Gini coefficient & 0.35 & $0.35(0.015)$ \\
\hline Total group income & 512.16 & $518.98(16.40)$ \\
\hline
\end{tabular}

Note. Robust standard errors in parentheses, clustered by group.

Figure 3: Laffer Curves
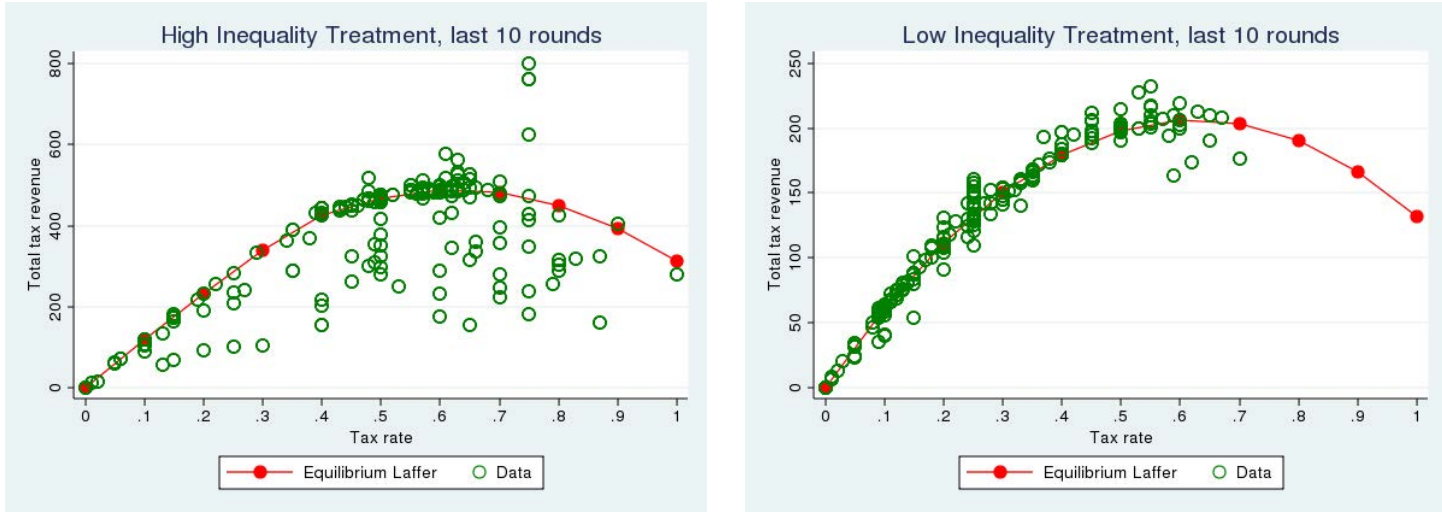
supply and lower total income in both inequality treatments, in exchange for a reduction in after-tax income inequality. Second, deviations from the theoretical frontiers in Low inequality treatment are minimal, balanced between points above and below the frontiers and are not correlated with the tax rate (as seen from the right panels of Figures 2 and 3). Third, in the High inequality treatment deviations from the theoretical efficiency-equity frontier are significant. Fourth, as shown in Table 6, these deviations are entirely along the efficiency dimension, and with no significant difference in the equity dimension; furthermore, Table 5 shows that this is driven by the undersupply of labor by the highest productivity agent (that with productivity $w_{i}=35$ ). The figures also show that this undersupply does not seem to depend on the tax rates: undersupply of aggregate labor is observed for both high and low tax rates.

\section{Result 3:}

(a) Higher tax rates lead to lower total income irrespectively of the inequality level, as predicted by the efficiency-equity tradeoff.

(b) In the Low inequality treatment, the data closely track the efficiency-equity frontier and theoretical Laffer curve, while in the High inequality treatment the deviations from these frontiers are significantly negative in the efficiency dimension.

\section{Extensions: Political Institutions and Social Prefer- ences}

\subsection{Comparison of Direct Democracy and Representative Democ- racy}

In this section we compare how two political regimes, direct democracy (DD) and representative democracy (RD), affect implemented tax rates, voting behavior, and labor supply.

Implemented Taxes. Table 7 summarizes the implemented tax rates in each political regime in each inequality treatment. The results of a regression analysis confirm that in each political regime, higher inequality leads to significantly higher level of redistribution. ${ }^{19}$ Moreover, there is no significant difference between the average or median implemented taxes in the DD and RD regimes, for each inequality treatment. ${ }^{20}$

\footnotetext{
${ }^{19}$ For each political regime, we regress implemented taxes on a dummy variable for the High inequality treatment, clustering observations by group. Estimated coefficients are positive and significant: $\beta=0.21$ $(p<0.01)$ for DD regime and $\beta=0.28(p<0.01)$ for $\mathrm{RD}$ regime.

${ }^{20}$ To reach this conclusion we regress implemented taxes on a dummy variable for the RD regime, for each inequality treatment separately, clustering observations by group. The estimated coefficient is not statistically different from zero for either inequality treatment: $\beta=0.06(p=0.25)$ in the High inequality treatment and $\beta=0.01$ ( $p=0.92)$ in the Low inequality treatment. This is further confirmed by a Wilcoxon Rank-sum test that fails to reject the null hypothesis that distributions of implemented taxes are the same in the DD and RD regimes, for both the High and Low inequality treatments $(p=0.06$ in High inequality treatment and $p=0.70$ in Low inequality treatment).
} 
Table 7: Implemented Taxes in each Regime

\begin{tabular}{ccccc}
\hline \hline & \multicolumn{2}{c}{ High Inequality, $t^{*}=0.53$} & \multicolumn{2}{c}{ Low Inequality, $t^{*}=0.28$} \\
& mean (st err) & median & mean (st err) & median \\
\hline DD & $0.47(0.04)$ & 0.50 & $0.26(0.03)$ & 0.25 \\
RD & $0.54(0.03)$ & 0.57 & $0.27(0.07)$ & 0.23 \\
\hline \hline
\end{tabular}

Note. Robust standard errors are in parentheses, clustered by group.

Voting Behavior. Besides the predictions about equilibrium tax rates as a function of the distribution of wage rates, the model also makes more specific predictions about voter behavior in the two institutional regimes. Specifically, in DD, all voters, regardless of productivity, have a dominant strategy to propose their most preferred tax rate, assuming all voters supply labor optimally conditional on any tax rate. Similarly, in RD, voters have a dominant strategy to vote for the candidate who proposed the more preferred of the two candidates' tax rates, once again under the assumption that all voters supply labor optimally. Moreover, in both political regimes, theory predicts that ideal tax rates of agents are monotonic in agents' productivities.

We test these predictions by comparing ideal tax rates of agents predicted by theory with median taxes proposed by experimental subjects in the DD treatment and with empirically estimated ideal tax rates from the RD treatment. Estimation of empirical ideal taxes in RD regime utilizes voting data and backs out a tax rate which minimizes the utility loss from the voting mistakes for each productivity separately in each inequality treatment. To define the utility loss from voting mistakes, we first organize voting data in the following way. For each productivity and each inequality treatment separately, we display simultaneously the two proposals that are offered in each election and the proposal the voter of that productivity voted for (see Figure 5 in Appendix B). The horizontal axis represents the tax rate proposed by the candidate the voter voted for, and the vertical axis corresponds to the tax rate proposed by the other candidate. Each panel also has two crossing line segments. Those line segments represent pairs of tax proposals that the voter in theoretically indifferent between. One of the segments, the upward sloping one, obviously is the diagonal. The other, downward sloping line represent pairs that are equidistant from the voter's ideal tax rate. The two lines intersect at the ideal tax rate of the voter. Therefore, correct votes are in north and south quadrants. Incorrect votes are in the east and west quadrants. ${ }^{21}$ Utility loss is defined as the shortest distance from a point in the east or west quadrant to the closest indifference line.

Figure 4 summarizes theoretically predicted and empirically estimated ideal tax rates of agents in both political regimes and both inequality treatments. While there are some minor discrepancies between empirical and theoretical ideal taxes ${ }^{22}$, our data in both political

\footnotetext{
${ }^{21}$ For high productivity voters whose ideal point is zero tax, the west and south quadrants do not exist, reflecting the fact that it is always optimal for these voters to vote for the lower tax rate.

${ }^{22}$ In the Low inequality treatment, the ideal tax rates of two lowest productivity agents are not perfectly ordered by productivity in DD regime, but neither one is significantly different from the theoretical one, nor are they significantly different from each other. Second, average proposed taxes by the highest productivity workers are above 0.00. This is expected, since any variation in behavior of these types produces this result, as negative taxes are not allowed. The positive tax rate proposals by the high types is also consistent with
} 
Figure 4: Predicted and Empirical Ideal Tax Rates, by productivity.
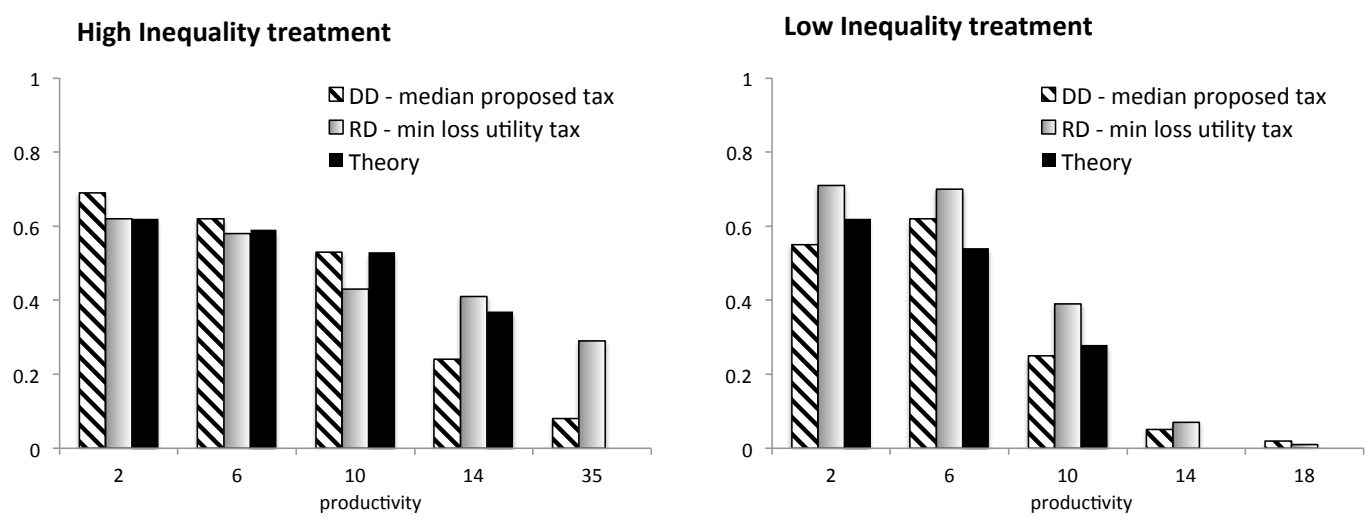

regimes clearly supports the main prediction, the monotonicity result. In both political regimes, empirical ideal taxes are monotonic in agents' productivities.

A final qualitative theoretical prediction about proposals in DD regime is that the median proposal will be submitted by the median productivity type. While this does not always occur in our data, it is the modal observation: the median type submits the median proposal $52 \%$ of the time in DD-high treatment $58 \%$ of the time in DD-low treatment.

Labor Supply. The labor supply behavior in both political regimes is very similar as can be seen in Table 12 in Online Appendix 3, in which we reports analysis parallel to Table 4 conducted separately for each political regime. ${ }^{23}$

Welfare. Finally, we conduct welfare analysis similar to the one reported in Section 4.3 separately for each political regime. Tables 13 and 14 (Online Appendix 3) replicate Table 6, which reported average efficiency-equity measurements for each political regime. Figures 6 and 7 (Online Appendix 3) replicate Figure 2 and plot all the equity-efficiency pairs together with the theoretical benchmark (equity-efficiency frontier). We do not observe any significant aggregate differences between political regimes in terms of observed efficiency or equity in both inequality treatments. Moreover, both political regimes closely track theoretical predictions.

finding by Feddersen et al. (2009) who report that voting behavior is more generous to others, the less likely a voter is pivotal. In DD-high, proposals by the high productivity types are pivotal only $7 \%$ of the time.

${ }^{23}$ Regression analysis similar to the ones reported in Table 5 performed separately for each political regime suggests that the undersupply of labor by the $w=35$ types in the High Inequality treatment when the investment constraint was binding $(t<0.36)$ was significant in the DD treatment, but not significant in the RD treatment. Further, in the Low Inequality treatment, the slope of the lowest productivity type's normalized labor supply is significantly less than the predicted value of 0.8. However, this has very little economic significance, as this agent type is predicted to supply very little labor for any tax rate compared to other agent types. 


\subsection{Social Preferences}

\subsubsection{Theoretical Predictions of Model with Social Preferences}

In this section we extend our theoretical analysis to characterize how labor supply and equilibrium taxes are affected by social preferences. ${ }^{24}$ This model is a natural one for considering the effects of other-regarding preferences. Indeed, in this framework social preferences of almost any kind will affect both labor supply decisions of agents as well as their indirect preferences over tax rates. We explore in depth two commonly used social preferences models: altruism and inequity aversion.

Preferences for altruism. $U_{i}^{A}(w, x, t)$ denotes the altruistic utility function of agent $i$ :

$$
U_{i}^{A}(w, x, t)=U_{i}\left(w_{i}, x_{i}, t\right)+A \frac{1}{n-1} \sum_{j \neq i} U_{j}\left(w_{j}, x_{j}, t\right)
$$

where parameter $A \geq 0$ measures $i$ 's altruism, the weight $i$ puts on the average payoff of others in the society, and $U_{i}\left(w_{i}, x_{i}, t\right)$ is defined as before by equation (1). The standard model without social preferences is nested in altruism model and corresponds to $A=0$.

Fehr-Schmidt Preferences. Order agents according to their productivity from the lowest $i=1$ to the highest $i=n . U_{i}^{F S}(w, x, t)$ denotes the Fehr-Schmidt utility function of agent $i$ :

$$
\begin{aligned}
U_{i}^{F S}(w, x, t)=U_{i}\left(w_{i}, x_{i}, t\right) & -\frac{\alpha}{n-1} \cdot \sum_{j=1}^{n} \max \left(U_{j}\left(w_{j}, x_{j}, t\right)-U_{i}\left(w_{i}, x_{i}, t\right), 0\right)- \\
& -\frac{\beta}{n-1} \cdot \sum_{j=1}^{n} \max \left(U_{i}\left(w_{i}, x_{i}, t\right)-U_{j}\left(w_{j}, x_{j}, t\right), 0\right)
\end{aligned}
$$

where the second term measures utility loss from disadvantageous inequality in payoffs and the third term measures utility loss from advantageous inequality in payoffs. The standard assumption in the literature is that $0 \leq \beta \leq \alpha \leq 1$, i.e. individuals experience greater utility loss from inequality when their payoff is below average than when their payoff is above average. The standard model without social preferences is nested in the inequity aversion model and corresponds to $\alpha=\beta=0$.

Labor supply with social preferences. Proposition 2 below establishes two results. First, altruism leads to higher labor supply compared to the selfish model, for all values of $A$ and for all productivity levels. Second, inequity aversion leads to higher individual labor supply if and only if an individual's productivity rank is sufficiently high. Thus, for any tax rate, relatively high productivity inequality averse individuals will supply more labor than a selfish individual, while relatively low productivity workers will supply less labor.

\section{Proposition 2 (Labor Supply):}

1. The optimal labor supply of an agent with productivity $w_{i}$ and altruism parameter $A$ is $x_{i}^{\mathrm{A}}\left(w_{i}, t\right)=\left[1-t+\frac{(1+A) t}{n}\right] w_{i}$. The more agent $i$ cares about the average payoff of other agents the more labor he will supply for a given tax rate $t$. That is, $x_{i}^{\mathrm{A}}\left(w_{i}, t\right)>$ $x_{i}^{*}\left(w_{i}, t\right)$ and $\frac{d x_{i}^{\mathrm{A}}\left(w_{i}, t\right)}{d A}>0$ for all $A \geq 0$.

\footnotetext{
${ }^{24}$ All proofs of results in this section are available in Online Appendix 1.
} 
2. The optimal labor supply of an individual with productivity $w_{i}$ and Fehr-Schmidt parameters $\alpha$ and $\beta$ is: $x_{i}^{F S}\left(w_{i}, t\right)=\left(1-t+\frac{1}{\mu_{i}} \cdot \frac{t}{n}\right) w_{i}$ where $\mu_{i}=1+\frac{\alpha(n-i)-\beta(i-1)}{n-1}>0$ for all $1 \leq i \leq n$. Inequality averse agents with high productivity, those with $i>\frac{\alpha n+\beta}{\alpha+\beta}$, supply more labor than their selfish counterparts, while inequality averse agents with low productivity, those with $i \leq \frac{\alpha n+\beta}{\alpha+\beta}$ supply less labor than their selfish counterparts.

Equilibrium tax effects of social preferences. Altruism and inequity aversion affect equilibrium taxes in opposite ways. A society of altruists prefers lower taxes, as everyone is concerned, at least to some degree with efficiency, which declines when taxes increase. Thus, a small increase in altruism will result in a lower ideal tax rate for each individual (unless the individual's ideal tax rate was already equal to 0). With inequity aversion, because $\mu_{m}>1$, at the margin the median voter is more concerned about reducing the payoff of higher productivity workers than increasing the payoff of lower productivity workers, even if this means lowering her own payoff. There are some minor second and third effects that can go the other way, under fairly weak conditions those other effects are small enough for the main intuition to hold.

Proposition 3 (Tax Rates). Assume $n>3$ and $w_{m}^{2}<\frac{1}{n} Z$.

1. The ideal tax rate of the altruistic median productivity agent with $0<A \leq 1$ is lower than that of the selfish agent with $A=0$, i.e. $t_{m}^{A}<t_{m}^{*}$.

2. If individuals have inequality averse preferences such that $0<\beta \leq \alpha \leq \bar{\alpha}(\beta, n)$, then the ideal tax rate of the median productivity individual is strictly higher than that individual's ideal tax rate would be if $\alpha=\beta=0$, i.e. $t_{m}^{F S} \geq t_{m}^{*}{ }^{25}$

In principle, one could extend the analysis above to allow for heterogeneous social preferences. For the altruism model all the results of Propositions 2 and 3 continue to hold with heterogeneity. Altruistic agents will work harder and prefer a higher tax rate than selfish agents, regardless of the distribution of altruistic preferences in the population. The implications of heterogeneity for inequity averse agents is much more complicated because the impact of social preferences on labor supply and ideal tax rates would now be two dimensional problem, depending on both worker productivity and individual inequity aversion. One possible way to build in heterogeneity is to allow for two types of agents, selfish and inequity averse with parameters $(\alpha, \beta)$. We conjecture that in such a mixture-of-types model the main results would go through: in the labor market, lower income inequity averse workers will supply less labor and higher income inequity averse workers more labor; and the median ideal tax rate will be higher compared with the case of selfish preferences. However, a full analysis of this and other theoretical extensions to explicitly allow for heterogeneity of inequity aversion are beyond the scope of the present paper.

\footnotetext{
${ }^{25}$ The sufficient condition $\alpha \leq \bar{\alpha}(\beta, n)$ is stronger than needed. For $n$ sufficiently large, it can be dispensed with entirely because the second order terms vanish. For the experimental parameters, the condition reduces to $\alpha \leq 3 \beta$. See the online appendix for details.
} 


\subsubsection{Estimating Social Preference Models}

In this section we address the question of whether our data provide evidence of the presence of other-regarding preferences in the labor market and/or in the political domain. As observed in Section 4, we cannot reject the hypothesis that labor supply choices and implemented taxes are the same as the one predicted by the theory with selfish agents. However, the question remains whether our data might also be compatible with other-regarding preferences, based on the results developed above.

Labor Supply. For each inequality treatment, we estimate the altruism parameter $A \geq 0$ by finding the value of $A$ that minimizes the sum of squared deviations of the observed labor decisions from the theoretically predicted ones for that value of $A \geq 0$. We use a similar method to estimate the two inequity aversion parameters, $(\alpha \geq 0, \beta \geq 0)$. Table 8 presents the results of this estimation.

Table 8: Estimation results for altruism and inequity aversion effects on labor supply.

\begin{tabular}{ccc}
\hline \hline Treatment & Altruism $(A)$ & inequity aversion $(\alpha, \beta)$ \\
\hline High Inequality & 0 & $(0,0)$ \\
Low Inequality & 0.05 & $(0,0)$ \\
\hline \hline
\end{tabular}

Notes. Data pooled across DD and RD regimes.

With respect to altruism, we measure a positive but statistically insignificant $(p=0.44)$ altruism parameter $(A=0.05)$ only in the Low Inequality treatment. In all other cases, we also cannot reject the null that $A=0$ or $\alpha=\beta=0 .{ }^{26}$

Proposal Behavior. Social preferences would also affect the preferences of agents over the tax schedules. The data from the DD regime is perfectly suited for testing it because the median proposal mechanism is specifically designed to directly elicit each voter's ideal tax rate. Similar to what we did for the labor supply data, we estimate the altruism parameter, $A \geq 0$, and the inequity aversion parameters, $(\alpha \geq 0, \beta \geq 0)$, by minimizing the sum of square distances between the observed tax proposals and the optimal tax proposals for each productivity type, conditional on the parameters. The results are reported in Table 9 . We estimate a very small and insignificant $(\mathrm{p}=0.48)$ envy parameter $(\alpha=0.01)$ for the high inequality treatment. In all other cases the best fitting parameters equal 0.

\subsection{Empirical Equilibrium}

The results so far paint a picture of the aggregate data as being close to the theory based on selfish preferences with respect to (1) the qualitative comparative statics; (2) average

\footnotetext{
${ }^{26}$ The p-value is based on a Wald test for whether the sum of squared differences at the estimated parameters are significantly less than the sum of squared differences for the selfish model, with all parameters set equal to 0 . The estimates are constrained to be non-negative, in accordance with the theoretical model, so p-values are not reported in cases where the sum of squared differences is minimized at the null values of the parameters. In these cases the unconstrained estimates would be negative.
} 
Table 9: Estimation results for altruism and inequity aversion effects on DD voting.

\begin{tabular}{ccc}
\hline \hline Treatment & Altruism $(A)$ & inequity aversion $(\alpha, \beta)$ \\
\hline High Inequality & 0 & $(0.01,0)$ \\
Low Inequality & 0 & $(0,0)$ \\
\hline \hline
\end{tabular}

and median implemented tax rates; (3) the individual labor supply responses to tax rates (except for the $w_{i}=35$ workers); (4) the aggregate labor supply effect of taxes; and (5) voting behavior. However there is some heterogeneity across groups in the data. In this section we take a closer look at this variation, and in particular explore the possibility that deviations from the equilibrium tax rates may be driven by variation across groups with respect to expectations about labor supply responses to taxes.

Theoretically, deviations from equilibrium labor supply responses to tax rates, if correctly anticipated by voters, will lead to distortions in the political equilibrium tax rates. That is, the equilibrium tax rates in High and Low Inequality treatments derived in Section 2 were based on the assumption that all agents make optimal labor decisions at all tax rates, and all voters correctly anticipate this. However, to the extent that we find actual aggregate labor supply functions to be different from the theoretical ones, if these deviations vary systematically across groups, then one might expect rational candidates to propose different tax rates in the RD regime and agents to offer different tax proposals in the DD regime. Therefore, in this section we will connect the analysis of the labor and political markets and ask whether the variation in the labor supply across different groups is linked in this way to the variation in the implemented tax rates. We refer to tax rates that constitute an equilibrium relative to the empirical labor supply functions as an empirical equilibrium.

To do this, we construct three alternative models of "empirical equilibrium" (EE) tax rates that differ according to the method used to estimate the labor supply functions in a group. That is, we estimate empirical labor supply functions of each agent in each group, and then compute the empirical equilibrium tax rate for that group based on the estimated labor supply functions. The challenge is to obtain good estimates of the labor supply functions. To deal with this issue, rather than choosing one particular method to estimate labor supply, we apply three different alternative models to do this estimation. The first, EE1, uses only the data from the first 10 periods to estimate the labor supply functions of each group member, and uses this estimate to compute an adjusted median voter's ideal tax rate as the basis for the empirical equilibrium tax rate. The second, EE2, is similar, but uses the labor supply data from all 20 periods. The third model, EE3, takes a different approach. For each group EE3 is based only on the earnings of the median productivity worker across the ten trial tax rates in the first 10 periods; the EE3 tax rate is the one of these for which that agent experienced the highest earnings.

Table 10 shows the results of regressing predicted against observed tax rates, using all 400 observations from the 40 groups in the experiment. The observed tax rate in each group equals the median of that group's ten implemented taxes in periods 11-20. The predicted tax rate is calculated for each of the models EE1, EE2 and EE3 described above, as well as for the theoretical model based on individually optimal labor supply, derived in Section 2. 
Table 10: Regressions of predicted against observed tax rates.

\begin{tabular}{cccc}
\hline \hline & constant & slope & $R^{2}$ \\
\hline Theory & $-0.00(0.07)$ & $0.94(0.17)$ & 0.28 \\
EE1 & $0.23^{*}(0.06)$ & $0.12^{* *}(0.13)$ & 0.31 \\
EE2 & $0.23^{*}(0.07)$ & $0.11^{* *}(0.13)$ & 0.31 \\
EE3 & $0.12^{*}(0.06)$ & $0.32^{* *}(0.14)$ & 0.35 \\
\hline \hline
\end{tabular}

Notes. Robust standard errors are in the parentheses, clustered by group.

${ }^{*}$ is significantly different from $0,{ }^{* *}$ is significantly different from 1 .

The first model, based on the theoretical labor supply functions, is the only model that produces estimates close to the theoretical predictions. The first model has an estimated intercept equal to 0.00 and slope equal to 0.94 , and we cannot reject the hypothesis that they equal 0 and 1, respectively. Based on the coefficient estimates, all three EE models reject that hypothesis. In fact, for EE1 and EE2, one cannot even reject the hypothesis that the slope equals 0 . In terms of model fit, the $\mathrm{R}^{2}$ is slightly higher for the three EE models than the theoretical equilibrium model, but this does not take into account that we are implicitly burning some degrees of freedom by estimating the labor supply curves for each group and then feeding those estimates into each of the EE models. We interpret this finding as supportive of the basic theory. That basic theory obviously cannot explain variation in the data across groups, but the results in table show that on average its overall predictive accuracy is very good. In a sense, this just mirrors the results reported in Tables 3 and 7 and Figure 1, showing that average tax rates in the two inequality treatments are very close to their predicted values. The additional estimation to fit each group separately based on their own empirical labor supply functions, while explaining some of the variance across groups, does so at a cost in predictive accuracy.

\section{Conclusion}

This article presents the results from an experiment to explore the median voter theory of equilibrium income tax rates that produce distortions in labor supply. The experiment is novel in a number of ways, including combining a labor market with a political market, where preferences in the political market are endogenous and are determined by expectations about labor supply responses to taxes. The central focus was on four main questions. Does greater inequality ex ante lead to higher tax rates and more income redistribution? Are the implemented tax rates driven by the induced preferences of the median income voter? Do the implemented tax rates depend on the institutional rules governing the collective choice procedure? Do social preferences have a significant impact on labor supply responses to tax rates or to indirect voter preferences over tax rates?

The answer to the first question is unambiguously yes. Higher ex ante inequality in terms of worker wage rates leads to higher tax rates. The effect is significant and large in magnitude. The answer to the second question is related to the first: the implemented tax rates in both inequality treatments are almost exactly equal to the theoretical ideal tax rate of the median wage worker. The answer to the third question is negative. We 
do not observe any significant differences in labor supply or average implemented tax rates between the direct democracy institution and a representative democracy where tax rates are determined by candidate competition. While there are many other possible democratic collective choice procedures that one could examine, this third finding is at least suggestive of a robustness with respect to the finer details of majoritarian democratic choice procedures. The answer to the fourth question is also negative. We do not observe significant deviations from labor supply behavior or voting behavior of the sort that are implied by models of altruism or inequity aversion. The one exception is the labor market behavior under the DD-low treatment, where we estimate a small but significant altruism effect.

The findings from the experiment lead to some strong conclusions, but leave open a number of more difficult questions that are beyond the scope of the analysis presented here. There are at least two intriguing unanswered questions about behavior in these experiments. First there is the surprising result about undersupply of labor by the highest productivity workers in the high inequality treatment. Such behavior is inconsistent with selfish behavior as well as altruistic or inequality averse behavior. Second, we observe some variation in tax rates across different groups and across periods.

More general questions concern the robustness of our findings to richer environments. The findings are suggestive of rather general phenomena, but as a first exploration of these phenomena in the laboratory, our experimental environment was necessarily very stark. What happens if there are more agents, more complicated political institutions involving multiple layers and branches of government, progressive tax structures, or dynamic considerations such as income mobility or investment in human capital? The taxes we consider are purely redistributional, but many government expenditures are not purely redistributional and involve investments in public infrastructure, social insurance, and other categories that have a significant public good component. There are also interesting questions about the effect of tax rates on tax compliance, an issue that is beyond the scope of the present study. All of these issues are important to understand the relationships between public finance and political economy more deeply, and some of them are already being explored theoretically and empirically. We are hopeful that this paper opens the door for further investigation of these issues using laboratory experiments as a complement to theoretical and empirical studies.

\section{References}

[1] Alesina, A. and P. Giuliano. 2011. Preferences for Redistribution. in Jess Benhabib, Matthew O. Jackson and Alberto Bisin editors: Handbook of Social Economics, Vol. 1A. Amsterdam: North-Holland, 93-131.

[2] Andreoni, J. and J. Miller (2002) Giving According to GARP: An Experimental Test of the Consistency of Preferences for Altruism. Econometrica. 70(2): 737-753.

[3] Black, D. 1958. The Theory of Committees and Elections. Cambridge: Cambridge University Press. 
[4] Bolton, G. and A. Ockenfels (2000) ERC: A Theory of Equity, Reciprocity, and Competition. American Economic Review. 90: 166-93.

[5] Bolton, G. and A. Ockenfels (2006) inequity aversion, Efficiency, and Maximin Preferences in Simple Distribution Games: Comment. American Economic Review. 96: 190611.

[6] Carbonell-Nicolau, O. and E. Ok (2007). Voting over Income Taxation. Journal of Economic Theory 134: 249-86.

[7] Coughlin, P. (1992) Probabilistic Voting Theory. Cambridge University Press: Cambridge.

[8] Downs, A. 1957. An Economic Theory of Democracy. New York: Harper and Row.

[9] Durante, R., Putterman, and J. Van der Weele (2014). Preferences for Redistribution and Perception of Fairness: An Experimental Study. Journal of the European Economic Association, in press.

[10] Esarey, J., T. Salmon, and C. Barrilleaux (2012). What Motivates Political Preferences? Self-Interest, Ideology, and Fairness in a Laboratory Democracy. Economic Inquiry, 50(3): 604-24.

[11] Feddersen, T., S. Gailmard, and A. Sandroni (2009) Moral Bias in Large Elections: Theory and Experimental Evidence. American Political Science Review 103(2); 175192.

[12] Fehr, E. and K. Schmidt (1999) A Theory of Fairness, Competition, and Cooperation. Quarterly Journal of Economics, 114(3): 817-68.

[13] Fisman, R., S. Kariv, and D. Markovits (2007). Individual Preferences for Giving. American Economic Review. 97(5): 1858-76.

[14] Forsythe, R., J. Horowitz, N. Savin, and M. Sefton (1994). Fairness in Simple Bargaining Games. Games and Economic Behavior. 6: 347-69.

[15] Grosser, J. and E. Reuben. 2013. Redistribution and Market Efficiency: An Experimental Study. Journal of Public Economics 101: 39-52.

[16] Hinich, M. (1977) Equlibrium in Spatial Voting: The Median Voter Result is an Artifact. Journal of Economic Theory. 16: 208-19.

[17] Hochtl, W., J.-R. Tyran, and R. Sausgrubeer (2012). Inequality aversion and Voting on Redistribution, European Economic Review, 56:1406-21.

[18] Holcombe, R. (1977) The Florida System: A Bowen Equilibrium Referendum Process. National Tax Journal. 30: 77-84.

[19] Holcombe, R. and L. Kenny (2007) Evidence on Voter Prefernces from Unrestricted Choice Referendums. Public Choice. 131: 197-215. 
[20] Holcombe, R. and L. Kenny (2008) Does Restricting Choice in Referenda Enable Governments to Spend More? Public Choice. 136: 87-101.

[21] Keane, M. (2011) Labor Supply and Taxes: A Survey Journal of Economic Literature. 49: $961-1075$.

[22] Konrad, K. and F. Morath (2011). Social Mobility and Redistributive Taxation. Working paper \#2011-2, Max Planck Institute for Tax Law and Public Finance, Munich.

[23] Krawczyk, M. (2010). A Glimpse Through the Veil of Ignorance: Equality of Opportunity and Support for Redistribution. Journal of Public Economics, 94:131-41.

[24] Ledyard, J. (1984) "The Pure Theory of Large Two-Candidate Elections," Public Choice, 1984, 44(1), 7-41.

[25] McCarty, N., K. Poole, and H. Rosenthal (2006) Polarized America The Dance of Ideology and Unequal Riches. Cambridge: MIT Press.

[26] Meltzer, A. H., and Richard, S. F. (1981). A rational theory of the size of government. Journal of Political Economy 89 (Oct.): 914-927.

[27] Meltzer, A. H., and Richard, S. F. (1983). Tests of a rational theory of the size of government. Public Choice, 41, 403-418.

[28] Milanovic, B. (2000) The median-voter hypothesis, income inequality, and income redistribution: an empirical test with the required data. European Journal of Political Economy, 16, 367-410.

[29] Moulin, H. (1980) On Strategy-Proofness and Single Peakedness. Public Choice 35: 437-55.

[30] Mirlees, J. (1971) An Exploration in the Theory of Optimum Income Taxation. Review of Economic Studies 38: 175-208.

[31] Palfrey, T. and H. Rosenthal (1988) Private incentives in social dilemmas: The effects of incomplete information and altruism. Journal of Public Economics. 35: 309-32.

[32] Perotti, R., 1996. Growth, income distribution, and democracy: what the data say. Journal of Economic Growth 1, 149-187.

[33] Roberts, K. W. S. (1977). Voting over income tax schedules. Journal of Public Economics 8:329-340.

[34] Romer, T. (1975). Individual welfare, majority voting and the properties of a linear income tax. Journal of Public Economics, 4, 163-185.

[35] Tyran, J.-R. and R. Sausgruber. (2006) A Little Fairness may Induce a Lot of Redistribution in Democracy, European Economic Review 50(2): 469-85. 


\section{Appendix A. Proof of Proposition 1}

Proof of Proposition 1. Single-peakedness is established in two steps. Clearly, if $\frac{d^{2} U_{i}^{*}\left(w_{i}, t\right)}{d t^{2}}<$ 0 in the region $t \in[0,1]$, then single peakedness in the policy space follows immediately. From equation 3, we get:

$$
\begin{aligned}
\frac{d U_{i}^{*}\left(w_{i}, t\right)}{d t} & =-w_{i}^{2}\left(1-t+\frac{t}{n^{2}}\right)+\frac{1}{n} Z\left(1-2 \frac{n-1}{n} t\right) \\
\frac{d^{2} U_{i}^{*}\left(w_{i}, t\right)}{d t^{2}} & =\frac{n-1}{n^{2}}\left((n+1) w_{i}^{2}-2 Z\right)
\end{aligned}
$$

Thus, single-peakedness is guaranteed by concavity of $U_{i}^{*}$ for all individuals whose productivity is sufficiently low $\left(w_{i}^{2}<\frac{2}{n+1} Z\right)$. For relatively high productivity workers $\left(w_{i}^{2}>\frac{2}{n+1} Z\right)$, it is easy to show that $\frac{d U_{i}^{*}\left(w_{i}, t\right)}{d t}<0$ for all values of $t \in[0,1]$ :

$$
-w_{i}^{2}\left(1-t+\frac{t}{n^{2}}\right)+\frac{1}{n} Z\left(1-2 \frac{n-1}{n} t\right)<0 \Leftrightarrow w_{i}^{2}>Z \cdot \frac{n(1-2 t)+2 t}{n^{2}(1-t)+t}
$$

The last inequality is satisfied for all $w_{i}^{2}>\frac{2}{n+1} Z$ since $\frac{2}{n+1}>\frac{n(1-2 t)+2 t}{n^{2}(1-t)+t}$.

From the above argument, if $w_{i}^{2}>\frac{1}{n} Z$ then the ideal tax rate of the worker with productivity $w_{i}$ is zero. However, if $w_{i}^{2} \leq \frac{1}{n} Z$, then the ideal tax rate of worker with productivity $w_{i}$, denoted by $t_{i}^{*}$, can be written as

$$
t_{i}^{*}=\frac{n^{2}}{n^{2}-1} \cdot \frac{\frac{1}{n} Z-w_{i}^{2}}{\frac{2}{n+1} Z-w_{i}^{2}}
$$

It is easy to check that these $t_{i}^{*}$ are weakly monotone in the productivities. The third property follows immediately. QED 


\section{Appendix B. Voting in RD}

Figure 5: Voting Behavior in $\mathrm{RD}$ treatments.

\section{High Inequality Treatment}
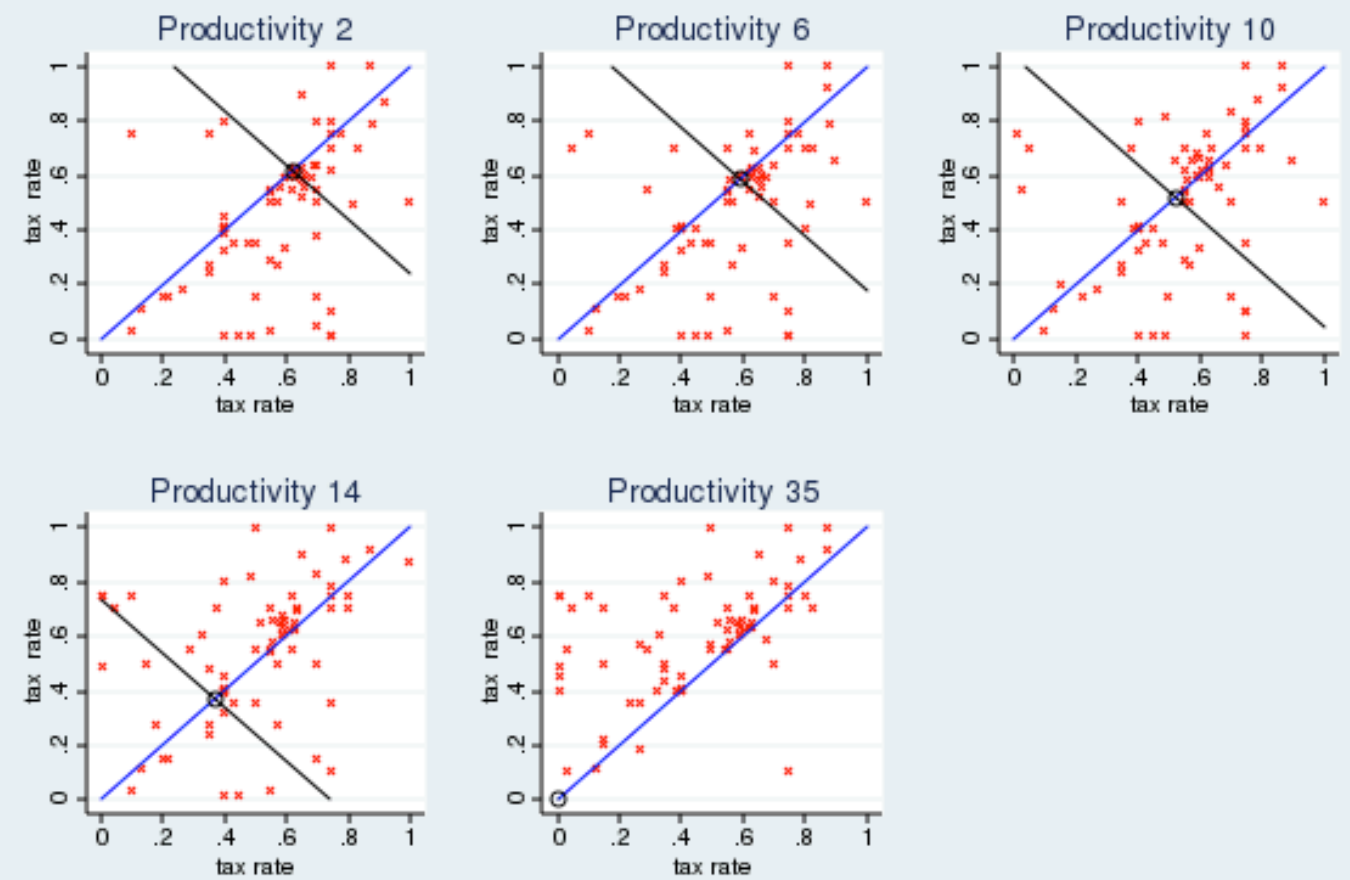

\section{Low Inequality Treatment}
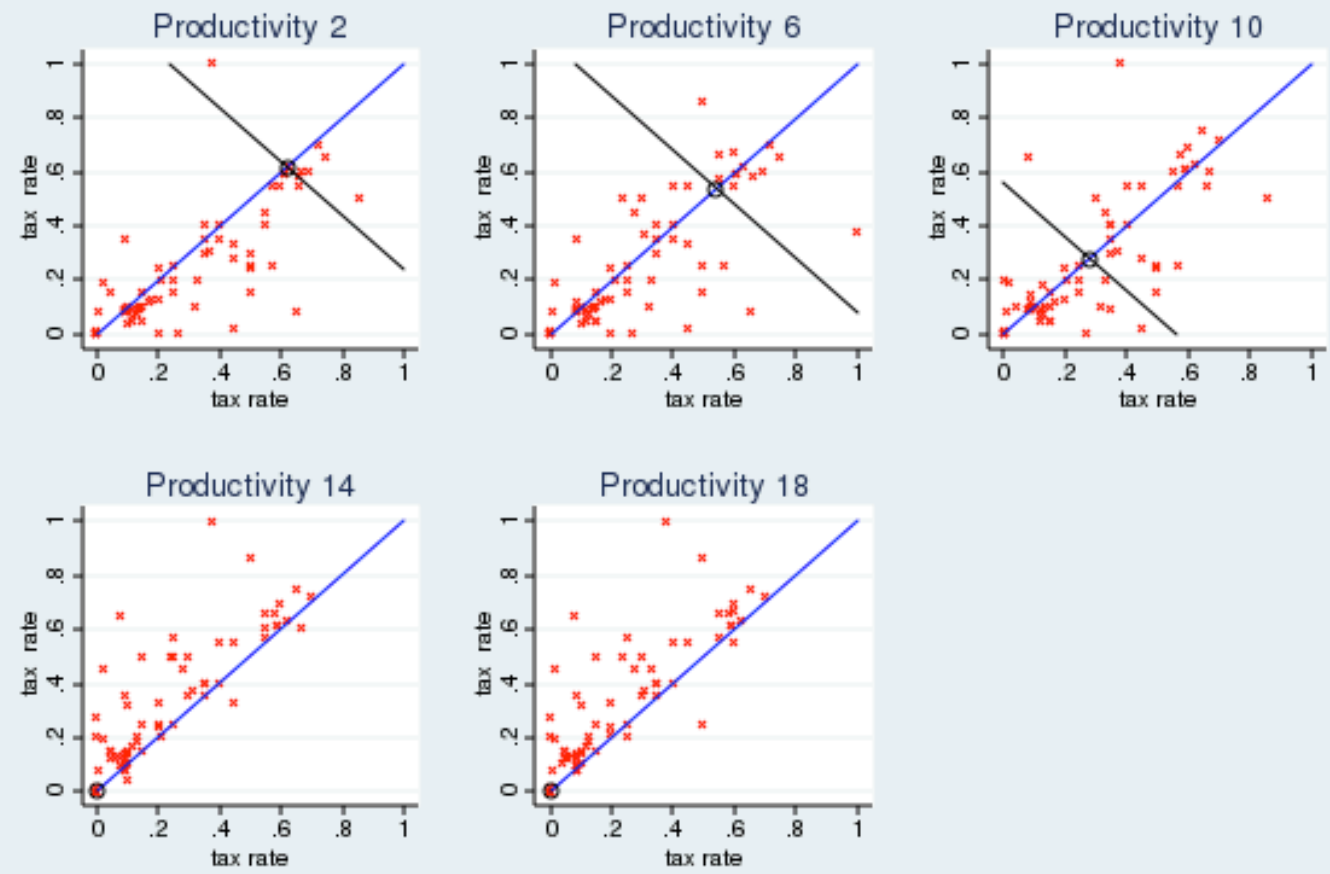